\title{
3-phosphoglycerate dehydrogenase deficiency, infantile/juvenile form
}

INSERM

\section{Source}

INSERM. (1999). Orphanet: an online rare disease and orphan drug data base. $\underline{3-}$ phosphoglycerate dehydrogenase deficiency, infantile/juvenile form. ORPHA:79351

3-Phosphoglycerate dehydrogenase deficiency (3-PGDH deficiency) is an autosomal recessive form of serine deficiency syndrome (see this term) characterized clinically in the few reported cases by congenital microcephaly, psychomotor retardation and intractable seizures in the infantile form and by absence seizures, moderate developmental delay and behavioral disorders in the juvenile form 